\title{
Food insecurity, malnutrition and mortality in Maewo and Ambae islands, Vanuatu
}

\author{
Andre MN Renzaho* $\dagger$ \\ Program Quality Advisor, Program Effectiveness, World Vision Australia and \\ Honorary Fellow, School of Health and Social Development, Deakin University, Australia
}

Submitted 4 April 2005: Accepted 17 November 2005

\begin{abstract}
Context: This paper reports on findings from the ex-post evaluation of the Maewo Capacity Building project in Maewo Island, Vanuatu, which was funded by World Vision Australia.

Objectives: To examine the extent to which the infrastructure and systems left behind by the project contributed to the improvement of household food security and health and nutritional outcomes in Maewo Island, using Ambae Island as a comparator. Setting: Two-stage cluster survey conducted from 6 to 20 July 2004, which included anthropometric measures and 4.5-year retrospective mortality data collection.

Participants: A total of 406 households in Maewo comprising 1623 people and 411 households in Ambae comprising 1799 people.

Main outcome measures: Household food insecurity, crude mortality rate (CMR), under-five mortality rate (U5MR) and malnutrition prevalence among children.

Results: The prevalence of food insecurity without hunger was estimated at $15.3 \%$ (95\% confidence interval (CI): 12.1, 19.2\%) in Maewo versus 38.2\% (95\% CI: 33.6, 43.0\%) in Ambae, while food insecurity with hunger in children did not vary by location. After controlling for the child's age and gender, children in Maewo had higher weight-for-age and height-for-age $Z$-scores than children of the same age in Ambae. The CMR was lower in Maewo $(\mathrm{CMR}=0.47 / 10000$ per day, 95\% CI: 0.39, 0.55) than in Ambae $(\mathrm{CMR}=0.59 / 10000$ per day, 95\% CI: $0.51,0.67)$ but no difference existed in U5MR. The major causes of death were similar in both locations, with frequently reported causes being malaria, acute respiratory infection and diarrhoeal disease.

Conclusions: Project initiatives in Maewo Island have reduced the risks of mortality and malnutrition. Using a cross-sectional 'external control group' design, this paper demonstrates that it is possible to draw conclusions about project effectiveness where baseline data are incomplete or absent. Shifting from donor-driven evaluations to impact evaluations has greater learning value for the organisation, and greater value when reporting back to the beneficiaries about project impact and transformational development in their community. Public health nutritionists working in the field are well versed in the collection and interpretation of anthropometric data for evaluation of nutritional interventions such as emergency feeding programmes. These same skills can be used to conduct impact evaluations, even some time after project completion, and elucidate lessons to be learned and shared. These skills can also be applied more widely to projects which impact on the longer-term nutritional status of communities and their food security.
\end{abstract}

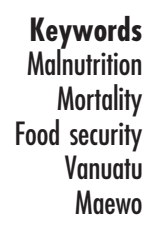

Food insecurity, defined as the inability of individuals, households and communities to acquire appropriate and nutritious food on a regular and reliable basis, using socially acceptable means, ${ }^{1}$, is a serious problem threatening the lives of million of people worldwide. The end product of food insecurity is malnutrition. Data

†Correspondence address: World Vision Australia, 1 Vision Drive, East Burwood, Victoria 3151, Australia. on the effect of malnutrition on child mortality from 53 countries indicate that $56 \%$ of all deaths among children were attributable to acute malnutrition, but $83 \%$ of all malnutrition-related deaths were attributable to mild-tomoderate malnutrition ${ }^{2}$. These findings suggest that, even though the relative risk of dying from malnutrition is greater in children with severe malnutrition, the proportion of deaths due to mild-to-moderate malnutrition, which is the form most prevalent in cases of food insecurity, is greater than that due to severe malnutrition. 
Current estimates indicate that the number of people suffering from chronic hunger is growing worldwide, with a recent report by the Food and Agriculture Organization of the United Nations estimating that 842 million people were chronically hungry in 1999-2001: 798 million in the developing world, 10 million in the industrialised countries and 34 million in the transition countries ${ }^{3}$. An annual trend analysis reported an increased rate of 5 million chronically undernourished people per year and a malnutrition-related death rate in the under-fives of 6 million children per year ${ }^{4}$.

While the nature of food insecurity tends to be similar in developing and developed countries ${ }^{5}$, the environmental setting in which it occurs differs considerably. In African countries, drought, armed conflicts, inadequate agricultural policies and poor governance have combined to affect household livelihood, and this has been worsened by the current HIV/AIDS epidemic (see Table $1^{6,7}$ ). As a consequence of the HIV epidemic, many farms have been left uncultivated as economically active adults continue to die, leaving orphans and elderly people at risk of hunger and malnutrition. Thus, it is currently estimated that some 60 to $70 \%$ of farms in sub-Saharan Africa have suffered labour losses as a result of HIV/AIDS ${ }^{3}$. In the Pacific region, however, the causes of food insecurity have included high population density, limited human resources, lack of skilled labour due to high migration within islands and overseas, limited access to markets due to difficulty of community outreach and inter-island transportation, declining soil fertility, land ownership issues and natural disasters ${ }^{5,8}$. For example, it is currently estimated that Vanuatu has nine active volcanoes, four of which are submarine ${ }^{5}$.

Addressing food insecurity has varied depending on the precipitating factors, ranging from food aid programmes in the form of humanitarian assistance such as in the Great Lakes region of Africa (Burundi, Uganda, Democratic Republic of Congo and Rwanda) $)^{9,10}$, Lesotho and Mozambique ${ }^{11}$ to agricultural trade in Vietnam, teaching children how to plant, grow and eat nutritious food in Panama, and developmentoriented projects in Kenya ${ }^{3}$.

Table 1 Prevalence of HIV among adults and the food and nutrition situation in selected sub-Saharan African countries

\begin{tabular}{lcccc}
\hline & $\begin{array}{c}\text { \% Adults } \\
\text { living } \\
\text { with HIV* }\end{array}$ & $\begin{array}{c}\text { \% Population } \\
\text { in need of } \\
\text { food aid }\end{array}$ & $\begin{array}{c}\text { \% Stunting } \\
\text { in under-5s† }\end{array}$ & $\begin{array}{c}\text { \% Wasting } \\
\text { in under-5s† }\end{array}$ \\
\hline Lesotho & 29.6 & 30.0 & 34.7 & 7.5 \\
Malawi & 14.3 & 29.0 & 49.0 & 6.0 \\
Mozambique & 12.1 & 3.0 & 43.8 & 5.5 \\
Swaziland & 38.2 & 24.0 & 40.0 & 2.2 \\
Zambia & 16.7 & 26.0 & 39.9 & 4.4 \\
Zimbabwe & 24.9 & 49.0 & 41.3 & 7.3 \\
\hline
\end{tabular}

* Data from reference 6

†Data from reference 7 .
However, while humanitarian assistance programmes a subsection of international aid programmes along with development aid programmes - have successfully put in place policies and practice for monitoring programme outputs $^{12,13}$, studies assessing the impact of international aid programmes remain scarce ${ }^{12}$. The lack of an impact evaluation framework for international aid programmes has been referred to as "methodological anarchy', Many factors have contributed to this situation, such as the lack of consensus in the international aid sector on what constitutes 'impact'; non-governmental organisations' lack of skill, policies or practice required for an adequate assessment of programme impact ${ }^{12}$; confusion over what constitutes a hierarchy of evidence; and whether hierarchy of evidence should take precedence over methodological appropriateness when planning an impact evaluation ${ }^{15,16}$.

In addition, evaluation of international aid programmes continues to be driven and motivated by the interests of funding agencies as a tool to demonstrate accountability rather than proving programme effectiveness. In Hansch's words: 'aid agencies have been conditioned through years of reporting to donors by accounting standards that focus on what is known, not estimated. As a result, aid agencies avoid reporting impact altogether and instead report softer data, such as how many people were helped, or output data, such as how many commodities were transported and delivered ${ }^{13}$.

In response to this gap, World Vision Australia has developed a number of strategies to assess the long-term impact of its programmes. The present paper examines an ex-post evaluation of the Maewo Capacity Building project, examining the impact of the project five years after completion, with particular emphasis on the impact on the well-being of children and the mobilisation of the wider community. More broadly, the paper attempts to demonstrate that it is not only possible but also extremely useful to draw conclusions about project impact, even some time after the project completion, where baseline data are incomplete or absent.

\section{The Maewo Capacity Building project}

From 1997 to 1999, World Vision Australia implemented a capacity-building project in Maewo Island, Vanuatu. The project had three components. The basic health and sanitation component aimed to reduce the incidence of malaria, diarrhoea, skin and respiratory infections in the target communities by $50 \%$ or more. Strategies implemented to achieve this objective included: training the community in preventive health-care, nutrition and sanitation practices; improving access to safe water by repairing damaged water supply systems; providing first aid/emergency medical supplies; initiating environmentally sound rubbish disposal; and promoting the use of validated traditional medicines to treat common ailments. The community organising component aimed to 
strengthen community structure and create capacity to respond to community issues and concerns using minimum external resources and assistance. Strengthening of community structures involved establishing a core group of leaders in at least 17 of 23 villages with specific roles and responsibilities and a clear vision and goal for each community. The role of the established core group of leaders was to develop a comprehensive village plan, to organise monthly community meetings to discuss community projects and issues, and to put in place project committees and community participation strategies. The livelihood component aimed at ensuring that at least $80 \%$ of communities in Maewo Island had diversified food sources and/or increased income. Strategies included engaging the community in crop diversification, construction of three coconut oil processing machines, training the community in livelihood planning and management, and the provision of seeds, seedlings and agricultural tools.

At the end of the 3-year project, an end-of-project evaluation was undertaken ${ }^{17}$. However, the end-of-project evaluation was not objective-oriented as it was judged that three years of project implementation was not enough to yield the intended long-term results, which were reduction in mortality and malnutrition prevalence, and sustained household food security. Additionally, the project did not establish minimum baseline data against which to assess the project's progress and long-term impact on poverty alleviation. In the absence of baseline data, the objective of the evaluation was to examine the extent to which the infrastructure and systems left behind by the project, as documented in the end-of-project evaluation report ${ }^{17}$, contributed to improving and sustaining household food security, and improving health and nutritional outcomes in Maewo Island. Two questions were posited: (1) Did the project actually improve health and nutritional outcomes in the target population? and (2) Could observed health and nutritional outcomes be explained by other factors? Thus, the purpose of the study was to examine the extent to which the infrastructure and systems left behind by the project contributed to the improvement of household food security and health and nutritional outcomes in Maewo Island, using another island (Ambae) of similar characteristics as a control group. It was therefore hypothesised that, as a result of the infrastructure left behind by the Maewo Capacity Building project, Maewo would have better health and nutrition outcomes than Ambae.

\section{Methods}

\section{Study design, sample and procedure}

The study used a cross-sectional 'external control group' design ${ }^{16}$. Ambae Island was used as a control group because it was not exposed to the project, its proximity to Maewo and was the only island with sociodemographic and economic characteristics similar to those observed in
Maewo $^{18}$. In addition, since the completion of the Maewo Capacity Building project, the island has not been beneficiary of any international assistance.

The sample size calculation was related to the study's long-term outcome variables. The primary study's outcome specified that, at project completion and beyond, at least $80 \%$ of households in the target communities would have adequate food security (diversified food sources and/or increased income). The end-of-project evaluation carried out when the project phased out in 1999 estimated that $70 \%$ of the project beneficiaries had access to diversified food sources. Both the effect of the time elapsed since project completion and the effect of cyclone Ivy that devastated the two islands in 25-27 February 2004 were taken into account when calculating the sample size. Thus, it was hypothesised that, at the time of the evaluation, 65\% (instead of the projected 70\%) of the target households in Maewo would have adequate food security. Using the usual formula for sample calculation to compare two proportions from two populations ${ }^{19-21}$, it was estimated that a sample size of 666 households (333 in each island) would be sufficient to detect a difference of $15 \%$ between locations in the proportion of households with adequate food security with $80 \%$ power, a $5 \%$ significance level and a design effect of 2. This $15 \%$ difference represents the difference between 65\% of households with adequate food security in the population exposed to the project (Maewo) and 50\% in the nonexposed population (Ambae).

Data were obtained on 406 households in Maewo and 411 households in Ambae. Nine data collectors in each island, selected from the studied communities, were trained and collected the data between 6 and 20 July 2004 using a two-stage cluster sampling strategy ${ }^{10,22-24}$. This was the most efficient method of recruiting households, as villages were structured in such a way that geographic units were not generally sufficiently well organised to allow for systematic sampling ${ }^{10,24}$ and an accurate list of the population was non-existent.

At the first stage, tables listing villages per island were drawn up and their respective number of households estimated with the help of village chiefs. A mapping exercise with community leaders and staff at World Vision Vanuatu indicated that there were approximately 28 villages in Maewo and 25 villages in Ambae. Thirty clusters were randomly allocated in each island using a sampling interval such that the total number of clusters in each village was proportional to the total number of households in that village. This was achieved by using a sampling interval obtained by dividing the total number of households in each island by 30 . The first cluster in each island was determined by randomly drawing a number within the first sampling interval using a random number table $^{10}$. The sampling interval was then added to this number until 30 clusters were obtained in each island. A cluster was defined to include the minimum number of 
households in order to obtain the required sample size when 30 clusters were selected. Thus each cluster had a minimum of 11 households. A household represented an aggregate of persons who lived together either under the same roof or in different units in the same compound and who ate together or shared in common the household food.

The second stage was a selection of households that made up each cluster. In step 1 , the team of data collectors went to the centre of the village and spun a bottle to determine a random direction. The data collectors went in the direction of the bottle's neck from the centre to the edge of the village (villages are quite small) counting the number of households. In step 2, a number between 1 and the total number of households counted was chosen using a currency note (Vatu). The number chosen represented the first sampling point and the household chosen was interviewed. Once the interview of the first household was completed, the subsequent households to be interviewed were chosen by proximity, i.e. households physically closest to the selected household, until the required number of households per cluster was attained. In the case that data collectors reached the border of the village before the number of households required for a cluster was reached, they went to the centre of the village and repeated steps 1 and 2 . In the last step, where household members were absent at the time of the interview, data collectors returned there later if household members were likely to return or otherwise the household was replaced with the next household. Data on household food security, anthropometry among 6-59-month-old children and mortality data were collected by an intervieweradministered questionnaire. The interview took place in the participants' home, and informed consent was acquired.

\section{Measurements}

A 12-item food security scale was generated based on the Radimer-Cornell hunger scale ${ }^{25}$ and the US national measure of food security ${ }^{26}$ (Appendix). Although developed as a tool to assess food security in developed nations $^{25,27}$, the Radimer-Cornell hunger scale has been used successfully as a vulnerability assessment and early warning tool to assess the level of deterioration in the quality and diversity of the diet of a given population in emergency settings, such as during the economic crisis in Russia $^{28}$ and in Indonesia ${ }^{29}$. The instrument was found be reliable and valid ${ }^{27,29,30}$. The Radimer-Cornell hunger scale $^{25}$ as a measure of food security was chosen for several reasons: the instrument has been found to be quick to apply at household level as it does not require the physical audit of food stores; and food consumptionbased measures of food security such as individual intakes, household energy acquisition or dietary diversity are too detailed and labour-intensive, and above all require highly skilled data collectors who can measure accurately food quantities in terms of availability and consumption $^{31,32}$. With more than three-quarters of the population in Maewo and Ambae estimated never to have attended school or be educated only to primary level ${ }^{18}$, the implementation of a food consumption-based food security assessment methodology was not possible.

Prior to the proper implementation of data collection, the instrument was administered to community representatives, community workers and staff at World Vision Vanuatu for thematic analysis with respect to the clarity, relevance of the items to food insecurity and cultural sensitivity of the questions being asked. The trial phase established that, because the majority $(>75 \%)$ of the population on both islands are subsistence farmers, the focus on the lack of money as a reason for not consuming or accessing food could lead to misleading results. It was suggested that all questions relate to both food production (e.g. own harvest or food bartering) and food purchasing capacity. Also, the consultation found that breadwinners (mainly the head of household) are fed first, meaning that in case of dire situations they would be the last to be affected at the expense of children. This contrary to the current assumption in the developed world, that in cases of food insecurity there is a managed process whereby children are protected until the severe later stages ${ }^{25}$. Other issues identified included the confusion related to the cultural construction of concepts such as 'healthy and balanced diet' or the effect of the planting-harvest cycle in terms of food availability. All the identified issues were taken into account to produce the final instrument used in the survey, and specific questions were formulated in a manner that could detect reduced intake in children.

Three types of malnutrition were considered in this study: underweight measured by weight-for-age, stunting measured by height-for-age and wasting measured by weight-for-height. $Z$-scores as indicators of the nutritional status in children were used, with wasting defined as weight-for-height $Z$-score (WHZ) $<-2$, stunting defined as height-for-age $Z$-score $(\mathrm{HAZ})<-2$ and underweight defined as weight-for-age $Z$-score (WAZ) $<-2^{33,34}$.

Mortality rate was computed as follows ${ }^{35}$ :

$$
\begin{aligned}
\text { Mortality }= & \frac{\text { No. of deaths }}{\text { Recall period in days } \times \text { Mid-point population }} \\
& \times 10000,
\end{aligned}
$$

where mid-point population $=$ number of living $+1 / 2$ joining (live births, reunifications after an absence of at least 2 years) during recall period $-1 / 2$ people leaving (deaths, prolonged absence of at least 2 years) during the recall period.

Thus, the recall period for assessing mortality covered a 4.5-year period, i.e. from 1 January 2000 to the survey date (6-20 July 2004), averaging 1648 days. A calendar of events was constructed and used as a reference. All dates 
for newborns and deaths during the recall period were recorded. After consulting community representatives, for each death identified respondents were asked which of the following was the most likely cause of death: malaria, diarrhoeal diseases, acute respiratory infection, measles, malnutrition, domestic violence, cyclone or other.

\section{Data analysis}

Data were entered using SPSS for Windows, version 10.0 (SPSS Inc., Chicago, IL, USA) and analysed in Stata version 7.0 (Stata Corporation, College Station, TX, USA). To obtain the prevalence of food insecurity, interviewed households were classified into four categories: foodsecure, food uncertainty, food insecurity without hunger, and food insecurity with hunger in children. Households classified as food-secure were those which reported no food-insecure conditions, i.e. no affirmative answer to all 12 items plus those with one or two affirmative answers to the four items depicting inadequate access to food (questions 1, 2, 3 and 6), but not to any other items. Food uncertainty included households with three or four affirmative answers to items about inadequate access to food (questions 1, 2, 3 and 6) but without interrupted eating pattern (questions 4, 5, 7, 10 and 11) and/or reduced food intake (questions 8, 9 and 12). Food insecurity without hunger encompassed households with one or more affirmative answers to the items depicting distorted eating pattern at household level and/or among adults, but not in children (questions 4, 5, 7, 10 and 11). Food insecurity with hunger in children included households with one or more affirmative answers depicting distorted eating pattern in children or reduced intake (questions 8, 9 and 12) and at least two affirmative responses to items indicating distorted eating patterns at household level and/or among adults, but not to any items related to inadequate access to food. After this classification, the proportion of food insecurity and its 95\% confidence interval (CI) were computed.

In addition, the proportion of malnutrition and its 95\% CI were computed and mortality data were expressed per 10000 per day. The difference and its 95\% CI in outcome measures of interest were computed to compare Maewo and Ambae. To adjust for confounding factors when comparing Maewo and Ambae on anthropometric outcomes, standard multiple regression was used. The SVYSET command in Stata was used to specify clustering within the household (i.e. to account for greater similarities on many attributes of children from the same household), stratification and weighting prior to analysis.

\section{Results}

The demographic characteristics of the surveyed households are summarised in Table 2. A total of 817 households ( 406 households in Maewo and 411 households in Ambae) were surveyed, with an average size of 5.3 (95\% CI: 5.1, 5.5) people per household and an average income of 4090.5 Vatu (\$US 37) per month after controlling for seasonal variation in food availability. Approximately one in 18 households $(5.5 \%, 95 \%$ CI: $3.3,7.7 \%)$ was found to be female-headed. Overall, $14.1 \%$ of the population in the surveyed households was found to have never attended school, while $37.2 \%$ did not complete primary school and $13.7 \%$ dropped out of school at secondary level.

Table 3 summarises data on food insecurity in both islands. The proportion of households classified as 'foodsecure' was lower by 1.5 percentage points (95\% CI: -7.0 , $3.9 \%$ ) in Maewo than in Ambae, but an examination of the 95\% CI indicated that this difference was not statistically significant. However, Ambae recorded a significantly

Table 2 Summary of demographics and anthropometric measurements: Maewo versus Ambae

\begin{tabular}{|c|c|c|c|}
\hline Factor & Maewo & Ambae & All \\
\hline \multicolumn{4}{|l|}{ Household $(H H)$ characteristics } \\
\hline No. HHs visited & 406 & 411 & 817 \\
\hline Sample population & 1623 & 1799 & 3422 \\
\hline Average $\mathrm{HH}$ size & $5.7(5.4,5.9)$ & $5.0(4.7,5.3)$ & $5.3(5.1,5.5)$ \\
\hline Population $<5$ years of age (\%) & $15.1(14.3,15.9)$ & $14.9(14.0,15.8)$ & $14.9(14.3,15.5)$ \\
\hline Male:female ratio & $0.91(0.71,1.15)$ & $0.92(0.75,1.12)$ & $0.91(0.62,1.34)$ \\
\hline Female-headed HHs (\%) & $3.0(0.7,5.3)$ & $7.6(5.5,9.7)$ & $5.5(3.3,7.7)$ \\
\hline \multicolumn{4}{|l|}{ Child (6-59 months) characteristics } \\
\hline \multicolumn{4}{|l|}{ Gender ratio (boys-girls) } \\
\hline $6-29$ months & $0.78(0.66,0.90)$ & $1.31(1.17,1.45)$ & $1.03(0.93,1.13)$ \\
\hline $30-59$ months & $1.38(1.24,1.52)$ & $1.21(1.05,1.37)$ & $1.29(1.19,1.39)$ \\
\hline $6-59$ months & $1.11(1.00,1.21)$ & $1.25(1.13,1.37)$ & $1.18(1.10,1.26)$ \\
\hline Mean age (months) & $38.2(35.3,41.0)$ & $37.2(34.5,39.9)$ & $37.7(35.7,39.6)$ \\
\hline Mean weight (kg) & $14.3(13.7,14.8)$ & $12.9(12.4,13.5)$ & $13.6(13.2,14.0)$ \\
\hline Mean height $(\mathrm{cm})$ & $92.4(90.9,94.0)$ & $88.5(86.3,90.7)$ & $90.4(88.8,92.0)$ \\
\hline Mean HAZ & $-0.37(-0.76,0.03)$ & $-1.30(-1.66,-0.94)$ & $-0.85(-1.12,-0.58)$ \\
\hline Mean WHZ & $0.40(0.15,0.64)$ & $0.17(-0.02,0.37)$ & $0.28(0.13,0.44)$ \\
\hline Mean WAZ & $-0.06(-0.39,0.26)$ & $-0.98(-1.24,-0.71)$ & $-0.53(-0.75,-0.32)$ \\
\hline
\end{tabular}

HAZ - height-for-age Z-score; WHZ - weight-for-height Z-score; WAZ - weight-for-age Z-score. Values in parentheses are $95 \%$ confidence intervals. Bold font indicates a statistically significant regional difference, $P<0.05$. 
Table 3 Prevalence of food insecurity by location

\begin{tabular}{lrrr}
\hline Food security status & Maewo $(n=406)$ & Ambae $(n=411)$ & All $(n=817)$ \\
\hline Food security (\%) & $18.5(15.0,22.6)$ & $20.0(16.4,24.1)$ & $19.2(16.7,22.1)$ \\
Food uncertainty (\%) & $32.5(28.1,37.2)$ & $\mathbf{9 . 0}(6.6,12.2)$ & $20.7(18.0,23.6)$ \\
Food insecurity without hunger (\%) & $15.3(12.1,19.2)$ & $\mathbf{3 8 . 2}(33.6,43.0)$ & $26.8(23.9,30.0)$ \\
Food insecurity with hunger in children (\%) & $33.7(29.3,38.5)$ & $32.9(28.5,37.6)$ & $33.3(30.1,36.6)$ \\
\hline
\end{tabular}

Values in parentheses are $95 \%$ confidence intervals.

Bold font indicates a statistically significant regional difference, $P<0.05$.

lower proportion of households classified as 'food uncertain' (difference: $-23.5 \%$, 95\% CI: -28.9 , - 18.2\%) but a significantly higher proportion of households classified as 'food insecure without hunger' (difference: 22.9\%, 95\% CI: 17.1, 28.9\%) compared with Maewo. The proportion of households classified as 'food insecure with hunger in children' did not vary by location.

The overall prevalence of malnutrition was found to be 19.7\% (95\% CI: 15.8, 23.6\%) for underweight, 28.2\% (95\% CI: $23.8,32.6 \%$ ) for stunting and $8.8 \%$ (95\% CI: 5.9, 11.8\%) for wasting. The prevalence of underweight was significantly lower in Maewo than Ambae (difference: $-7.6 \%$, 95\% CI: $-13.6,-1.7 \%$ ) but no significant difference was detected for wasting (difference: $-2.8 \%$, $95 \% \mathrm{CI}:-11.9,6.1 \%$ ) and stunting (difference: $-0.8 \%$, 95\% CI: $-6.5,4.8 \%$ ) between the two locations. After adjusting for the child's age and gender, multiple regression coefficients (Table 4) also depicted relationship differences in children's nutritional status by location. The adjusted model incorporating age, gender and location explained $21.7 \%(P<0.0001)$ of the variance for WAZ, $17.9 \%(P<0.01)$ of the variance for HAZ and $17.5 \%$ $(P<0.01)$ of the variance for WHZ. The model suggests that children in Maewo Island had higher WAZ and HAZ, and thus were less likely to be underweight and stunted than children of the same age living in Ambae Island.
The overall crude mortality rate (CMR) and under-five mortality rate (U5MR) were found to be $0.53 / 10000$ per day (95\% CI: 0.48, 0.59/10 000 per day) and 0.78/10 000 per day (95\% CI: 0.62, 0.97/10 000 per day), respectively. CMR was significantly lower in Maewo than Ambae (difference: $-0.12 / 10000$ per day, 95\% CI: -0.23 , $-0.01 / 10000$ per day), while the U5MR was comparable in both islands (difference: $-0.05 / 10000$ per day, 95\% CI: $-0.37,0.05 / 10000$ per day) (see Table 5). Malaria, acute respiratory infection and diarrhoeal diseases were the frequently reported causes of death (Fig. 1). While in absolute terms the proportion of deaths due to malaria, diarrhoeal diseases and violence was lower in Maewo than Ambae, these differences were negligible.

\section{Discussion}

This study is the first to explore health and nutrition outcomes in Maewo and Ambae islands. Consistent with the study hypothesis, the evaluation found Maewo to have better health and nutritional outcomes than Ambae. With international data estimating the prevalence of underweight and stunting at 19.7 and 19.1\%, respectively, for Vanuatu ${ }^{36}$ (Fig. 2), the current data suggest that Maewo had a prevalence of underweight that was lower than the national average but a higher prevalence of

Table 4 Prevalence of stunting, underweight and wasting and adjusted* coefficients $(\beta)$ of HAZ, WAZ and WHZ as a function of demographic variables

\begin{tabular}{|c|c|c|c|c|c|c|c|}
\hline & \multirow[b]{2}{*}{$n$} & \multicolumn{2}{|r|}{ HAZ } & \multicolumn{2}{|r|}{ WAZ } & \multicolumn{2}{|r|}{ WHZ } \\
\hline & & $\% \dagger$ & Adjusted $\beta$ & $\% \ddagger$ & Adjusted $\beta$ & $\% \S$ & Adjusted $\beta$ \\
\hline \multicolumn{8}{|l|}{ Location } \\
\hline Ambae & 190 & $29.5(23.1,35.8)$ & Ref & $23.6(19.4,27.7)$ & Ref & $9.2(5.1,13.2)$ & Ref \\
\hline Maewo & 200 & $26.7(20.4,33.1)$ & $0.9(0.4,1.5)$ & $16.0(11.8,20.3)$ & $0.9(0.5,1.3)$ & $8.4(4.5,12.4)$ & $0.2(-0.1,0.5)$ \\
\hline \multicolumn{8}{|l|}{ Age group } \\
\hline $6-29$ months & 155 & $34.0(28.3,39.6)$ & Ref & $29.9(24.4,35.3)$ & Ref & $12.3(8.4,16.3)$ & Ref \\
\hline $30-59$ months & 235 & $25.6(21.4,29.8)$ & $0.0(-0.6,0.5)$ & $14.5(11.0,17.7)$ & $0.1(-0.3,0.5)$ & $7.0(4.5,9.5)$ & $-0.3(-0.7,0.0)$ \\
\hline \multicolumn{8}{|l|}{ Gender } \\
\hline Girls & 179 & $25.6(19.3,31.9)$ & Ref & $14.8(9.6,19.9)$ & Ref & $5.7(2.3,9.1)$ & Ref \\
\hline Boys & 211 & $30.5(24.4,36.6)$ & $\begin{array}{r}-\mathbf{0 . 6}(-\mathbf{1 . 1},-\mathbf{0 . 1}) \\
r^{2}=0.179(P<0.01)\end{array}$ & $23.8(18.1,29.5)$ & $\begin{aligned} & -0.7(-\mathbf{1 . 1},-\mathbf{0 . 2}) \\
r^{2} & =0.217(P<0.0001)\end{aligned}$ & $11.4(7.1,15.7)$ & $\begin{array}{r}-0.4(-0.7,-0.1) \\
r^{2}=0.175(P<0.01)\end{array}$ \\
\hline
\end{tabular}

HAZ - height-for-age Z-score; WAZ - weight-for-age Z-score; WHZ - weight-for-height Z-score.

Values in parentheses are $95 \%$ confidence intervals.

Bold font indicates a statistically significant difference from the reference (Ref), $P<0.05$.

${ }^{*}$ Model adjusted for factors in the table.

$\dagger$ Prevalence of stunting defined as $\mathrm{HAZ}<-2$.

$\ddagger$ Prevalence of underweight defined as $W A Z<-2$.

$\S$ Prevalence of wasting defined as $\mathrm{WHZ}<-2$. 
Table 5 Crude mortality rate (CMR) and under- 5 mortality rate (U5MR) by location

\begin{tabular}{lccc}
\hline & Maewo $(\mathrm{A})$ & Ambae $(\mathrm{B})$ & A-B \\
\hline CMR & & & \\
No. of deaths during recall period & 128 & 177 & \\
No. of newborns during recall period & 180 & 220 & \\
Mid-point population & 1649 & 1820 & \\
Deaths/10 000 per day & $0.47(0.39,0.55)$ & $0.59(0.51,0.67)$ & $\mathbf{0 . 1 2}(-\mathbf{0 . 2 3},-\mathbf{0 . 0 1})$ \\
U5MR & 31 & 36 & \\
$\quad$ No. of deaths during recall period & 245 & 268 & \\
Total $<5$ years of age & $0.76(0.54,0.99)$ & $0.81(0.59,1.03)$ & $-0.05(-0.37,0.05)$ \\
Deaths/10 000 per day &
\end{tabular}

Bold font indicates a statistically significant regional difference, $P<0.05$.

stunting. However, the above-reported national prevalences for underweight and stunting date back to $1983^{36}$. It is thus possible that the current national malnutrition prevalence could be higher than the above figures. Nevertheless, the prevalence of malnutrition (underweight, stunting and wasting) found in Maewo was far lower than the prevalence of malnutrition in Melanesia, Asia and Oceania and the average for all developing countries (see Fig. 2).

The current data also suggest that the CMR was lower in Maewo than Ambae. However, compared with national mortality averages as at $2003^{37}$ (CMR: 5/1000 inhabitants per year - equivalent to 0.14/10 000 per day, U5MR: 42/ 1000 live births per year - equivalent to $1.15 / 10000$ per day), the CMR was 3.5 and 4.4 times higher in Maewo and Ambae, respectively. In stark contrast, both islands recorded lower U5MR than the national average, with U5MR found to be 64.3\% lower in Maewo and 34.1\% lower in Ambae. Nevertheless, mortality and nutritional outcomes found in Maewo indicate that using existing community livelihood and resources yields desired sustained outcomes. We recently replicated this trend in other countries across Africa such as in Mozambique and Lesotho $^{11,38}$. This is in contrast to the current approach to international aid, which is overwhelmingly dominated by the reliance on external inputs when dealing with indigenous communities and thus making them dependent on international assistance ${ }^{39-41}$.

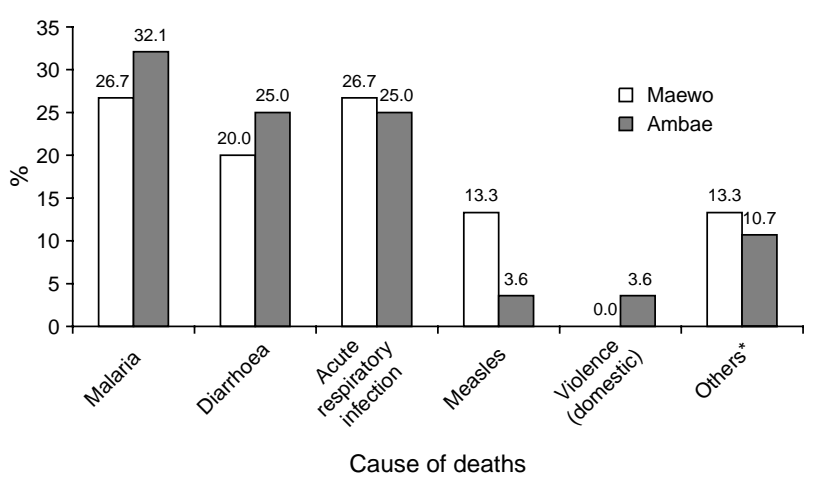

Fig. 1 Major causes (\%) of death by location. *Includes ulcers (stomach), liver diseases and cardiac diseases
Although Maewo displayed more favourable outcomes on food security indicators than Ambae, food insecurity remains a big problem in both islands and the percentage of households classified as food-insecure was comparable to that reported in countries undergoing economic crisis $^{28,29}$. Such a trend could be due to the fact that food insecurity results from many factors, ranging from socioeconomic, political and cultural to environmental, many of which were beyond the scope of the project as indeed is the case in many developing countries ${ }^{42}$. Another reason could be that both islands experienced a series of natural disasters, mainly cyclones ${ }^{43}$. Both islands were hit by cyclone Ivy on 25-27 February 2004 which destroyed many coconut palms, fruit and breadfruit trees and knocked down a number of homes and health posts. A number of families were left without shelter, food and access to medication ${ }^{43}$. Thus, the destruction of the livelihood system in Maewo and Ambae islands by the cyclone could have led to the high level of food insecurity observed in both islands, as the evaluation was undertaken just 4 months after cyclone Ivy hit.

\section{Limitations of the study}

The concept of ex-post evaluation is a relatively new one in this field. Our organisation has undertaken to conduct expost evaluation four to five years after project completion to assess the extent to which projects have contributed to poverty reduction. For the Maewo Capacity Building project, mortality was estimated over a period of 1648 days. Such an uncommonly long recall period may have affected the accuracy of the estimates. Nevertheless, the use of a calendar of events and of immunisation cards (given the adequate maternal and child health $(\mathrm{MCH})$ observed in the region), to check the last date the child attended the $\mathrm{MCH}$ centre prior to death and to validate the reported date of birth, may have minimised the risk of bias. Further mortality studies using a relatively shorter recall period in this region are recommended. In addition, information on bilateral leg oedema (indicating severe malnutrition irrespective of WHZ) was not collected due to the lack of skill of data collectors to detect oedema given their low educational level and the high likelihood of bias and misclassification. Thus the prevalence of wasting may have been 


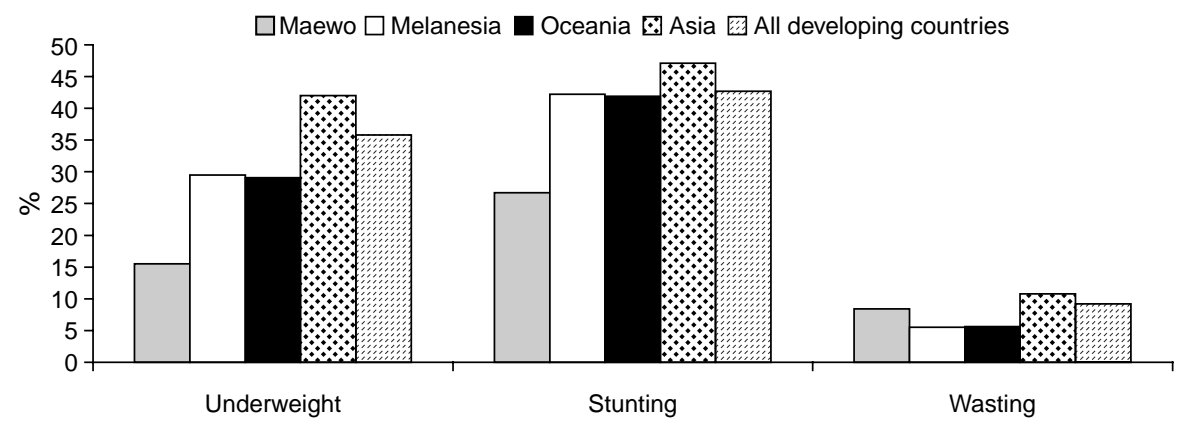

Fig. 2 Prevalence (\%) of malnutrition: Maewo versus international data. Source: adapted from reference 34

underestimated in this study. Furthermore, in the absence of an epidemiological surveillance system, the author relied on verbal reports on morbidity and cause of death.

\section{Conclusion}

This paper examines an ex-post evaluation of the Maewo Capacity Building project, examining the impact of the project five years after completion. Project initiatives in Maewo Island have improved the well-being of children by reducing the risks of mortality and malnutrition. This was achieved by investing in human capital in terms of transfer of skills, mobilising the wider community in the form of establishing community governance, maximising the use of existing resources, and by providing poor households with the opportunity to take advantage of the newly created possibilities. Using a cross-sectional 'external control group' design, this paper demonstrates that it is possible to draw conclusions about project effectiveness where baseline data are incomplete or absent. Shifting from donor-driven evaluations to impact evaluations (whether periodic, on project conclusion or ex-post) has greater learning value for the organisation, and greater value when reporting back to the beneficiaries about project impact and transformational development in their community. An impact evaluation can speak more to people than evaluations based on accountancy data and, put more simply, can the answer the question 'While we met all the requirements of the project, what was the real impact for the people?' Public health nutritionists working in the field are well versed in the collection and interpretation of anthropometric data for evaluation of nutritional interventions such as emergency feeding programmes. These same skills can be used to conduct impact evaluations, even some time after project completion, to elucidate lessons to be learned and shared. These skills can also be applied more widely to projects which impact on the longer-term nutritional status of communities and their food security.

\section{Acknowledgements}

The author is a Program Quality Advisor at World Vision Australia. Any opinions, findings and conclusions expressed in this paper are those of the author and represent a summary of consultations with the communities. These views do not necessarily reflect the views of World Vision Australia as an entity and its partners.

The author declares that this is an original manuscript which has not been submitted to or published in another journal. The author also declares that there has not been any financial or other relationship that might lead to a conflict of interest.

Special thanks go to the staff and community of World Vision Vanuatu.

\section{References}

1 Centre for Public Health Nutrition (CPHN). Food Security Options Paper: A Planning Framework and Menu of Options for Policy and Practice Interventions. Improving Nutrition in NSW Series. New South Wales, Australia: CPHN, 2003.

2 Pelletier DL, Frongillo EA, Schroeder DG, Habicht JP. The effect of malnutrition on child mortality in developing countries. Bulletin of the World Health Organization 1995; 73: 443-8.

3 Food and Agriculture Organization of the United Nations (FAO). The State of Food Insecurity in the World: Monitoring Progress Towards the World Food Summit and Millennium Development Goals. Rome: FAO, 2003.

4 Burgermeister J. Number of chronically hungry people is rising by $5 \mathrm{~m}$ a year. British Medical Journal 2005; 327: 1303.

5 Welegtabit SR. Food Security Strategies for Vanuatu. Working Paper Series No. 58. Bogor, Indonesia: Coarse Grains, Pulses, Roots and Tuber Crops Centre, 2001.

6 United Nations Programme on HIV/AIDS (UNAIDS). 2004 Report on the Global HIV/AIDS Epidemic: 4th Global Report. Geneva: UNAIDS, 2004.

7 Southern Africa Development Community. Regional Emergency Food Security Assessment Report. Harare: Food, Agriculture and Natural Resources Vulnerability Assessment Committee, 2002.

8 Food and Agriculture Organization of the United Nations (FAO). FAO and SIDS: Challenges and Emerging Issues in Agriculture, Forestry and Fisheries. Rome: FAO, 2004.

9 Levine S, Chastre C. Missing the Point: An Analysis of Food Security Interventions in the Great Lakes. London: Overseas Development Institute, 2004.

10 Renzaho AMN, Renzaho CC. In the shadow of the volcanoes: the impact of intervention on the nutrition and health status of Rwandan refugee children in Zaire two years on from exodus. Nutrition and Dietetics 2003; 60: 85-91.

11 Renzaho AMN, Mahony G, David J, Campbell D. World Vision Food Aid Program in Tete Province - Mozambique: 
Impact Evaluation and Documentation of Lessons Learned. Melbourne: World Vision Australia, 2004.

12 Hofmann C. Measuring the Impact of Humanitarian Aid Humanitarian Policy Group Research Paper No. 15. London: Overseas Development Institute, 2004.

13 Hansch S. Measuring program impact: lessons in evaluation from humanitarian aid. Democracy at Large 2005; 1(3). Also available at http://www.democracyatlarge.org/vol1_no3/vol1_no3_ITT_Measuring_Impact_print.htm. Accessed 10 October 2005.

14 Adelski E, Hill R, Mason J, MeClelland D, Muscat R. Complex Humanitarian Emergencies and USAID's Humanitarian Response. Washington, DC: Centre for Development Information and Evaluation, US Agency for International Development, 2000.

15 Petticrew M, Roberts H. Evidence, hierarchies and typologies: horses for courses. Journal of Epidemiology and Community Health 2003; 57: 527-9.

16 Habicht JP, Victora CG, Vaughan JP. Evaluation designs for adequacy, plausibility and probability of public health programme performance and impact. International Journal of Epidemiology 1998; 28: 10-8.

17 Boe S. Maewo Island Capacity Building Project: End of Project Report. Port Vila: World Vision Vanuatu, 1999.

18 Penama Provincial Council. Penama Five-year Social Development Plan: 2003-2007. Saratamata: Penama Province, Ministry of Home Affairs, Republic of Vanuatu, 2002

19 Wassertheil-Smoller S. Biostatistics and Epidemiology: $A$ Primer for Health Professionals. New York: Springer-Verlag, 1995.

20 Food and Agriculture Organization of the United Nations (FAO). Conducting Small-scale Nutrition Surveys: A Field Manual. Rome: FAO, 1990.

21 Campbell MJ, Julious SA, Altman DG. Sample sizes for binary, ordered categorical, and continuous outcomes in two group comparisons. British Medical Journal 1995; 311: $1145-8$.

22 Henderson RH, Sundaresan T. Cluster sampling to assess immunisation coverage: a review of experiences with a simplified sampling method. Bulletin of the World Health Organization 1982; 60: 253-60.

23 Salama P, Assefa F, Talley L, van der Veen A, Gotway C. Malnutrition, measles, mortality and the humanitarian response during a famine in Ethiopia. Journal of the American Medical Association 2001; 286: 563-71.

24 Médecins Sans Frontières. Nutrition Guidelines to Facilitate the Application of Fundamental Concepts and Principles Necessary for the Assessment of Nutritional Problems and The Implementation of Nutritional Programmes in Emergency Situations, 1st ed. Paris: Médecins Sans Frontières, 1995

25 Radimer KL, Olson CM, Campbell CC. Development of indicators to assess hunger. Journal of Nutrition 1990; 120 1544-8.

26 Hamilton WL, Cook JT, Thompson W, Buron L, Frongillo JE, Olson CM, et al. Household Food Security in the United States in 1995. Washington, DC: US Department of Agriculture Food and Consumer Service, Office of Analysis and Evaluation and Abt Associates, 1997.
27 Kendall A, Olson CM, Frongillo E Jr. Validation of the Radimer/Cornell measures of hunger and food insecurity. Journal of Nutrition 1995; 125: 2793-801.

28 Welch K, Mock N, Netrebenko O. Measuring hunger in the Russian Federation using the Radimer-Cornell hunger scale. Bulletin of the World Health Organization 1998; 76: 143-6.

29 Studdert L, Frongillo E, Valois P. Household food insecurity was prevalent in Java during Indonesia's economic crisis. Journal of Nutrition 2001; 131: 2685-91.

30 Frongillo EA Jr, Rauschenbach BS, Olson CM, Kendall A, Colmenares AG. Questionnaire-based measures are valid for the identification of households with hunger and food insecurity. Journal of Nutrition 1997; 127(Suppl.): 699S-705S.

31 Hatloy A, Torheim LE, Oshaug A. Food variety-a good indicator of nutritional adequacy of the diet? A case study from an urban area in Mali, West Africa. European Journal of Clinical Nutrition 1998; 52: 891-8.

32 Hoddinott J. Choosing Outcome Indicators of Household Food Security. Washington, DC: International Food Policy Research Institute, 1999.

33 National Center for Health Statistics. A Growth chart for International use in Maternal and Child Health Care. Guidelines for Primary Health Care Personnel. Geneva: World Health Organization, 1978.

34 Renzaho A, Burns C, Reidpath D. Measuring refugee Malnutrition in the under-fives: pit falls in practice. Mots Pluriels 2002; 21: 1-10. Also available at http://www.arts.uwa.edu.au/MotsPluriels/MP2102rbr.html/

35 Grein T, Checchi F, Escriba JM, Tamrat A, Karunakara U, Stokes C, et al. Mortality among displaced former UNITA members and their families in Angola: a retrospective cluster survey. British Medical Journal 2003; 327: 650.

36 de Onis M, Monteiro C, Akre J, Clugston G. The worldwide magnitude of protein-energy malnutrition: an overview from the WHO global database on child growth. Bulletin of the World Health Organization 2003; 71: 703-12.

37 United Nations Children's Fund. At a glance: Vanuatu [online], 2003. Available at http://www.unicef.org/ infobycountry/vanuatu_statistics.html. Accessed 10 March 2003.

38 Renzaho AMN. Evaluation of the Nthabiseng and Nazareth ADP Food Security Project in Lesotho: Summary of Key Achievements and Suggested Way Forward. Melbourne: World Vision Australia, 2005

39 Hoddinott J. Examining the Incentive Effects of Food Aid on Household Behaviour in Rural Ethiopia. Washington, DC: International Food Policy Research Institute, 2003.

40 Schmalbruch G. Linking relief and development starts with addressing food insecurity. The ACP-EU Courier 2003; 197: $48-9$.

41 World Bank. World Bank Aid and Reform in Africa: Lessons from Ten Case Studies. Washington, DC: World Bank, 2001.

42 Renzaho AMN. Human right to food security in refugee settings: rhetoric versus reality. Australian Journal of Human Rights 2002; 8: 43-56.

43 European Centre on Pacific Issues. Climate change: cyclones batter Pacific region. Europe Pacific Solidarity Bulletin 2004; 12: 10 
Appendix - Survey items used in Maewo and Ambae to assess household food security and their respective frequencies $(\%)$

\begin{tabular}{|c|c|c|c|c|}
\hline & Over the last 12 months: & Maewo & Ambae & All \\
\hline 1. & $\begin{array}{l}\text { Have there been occasions when you (head of the family) } \\
\text { worried that you could run out of food before you could } \\
\text { get money to buy more food before the next harvest? }\end{array}$ & 76.3 & 82.3 & 79.4 \\
\hline 2. & $\begin{array}{l}\text { Have there been occasions when you felt that you might } \\
\text { not be able to afford adequate food to feed all members } \\
\text { of the family during the planting-harvest season? }\end{array}$ & 69.4 & 80.4 & 75.0 \\
\hline 3. & $\begin{array}{l}\text { Have there been occasions when you felt like 'I wish } \\
\text { I could buy more food if I had more money' during } \\
\text { the planting-harvesting season? }\end{array}$ & 77.9 & 84.3 & 81.2 \\
\hline 4. & $\begin{array}{l}\text { Has your family eaten the same type of food for several } \\
\text { consecutive days because you did not have enough money } \\
\text { to buy different food all season around? }\end{array}$ & 62.0 & 69.9 & 66.0 \\
\hline 5. & $\begin{array}{l}\text { Has your family run out of food for more than a day on more } \\
\text { than two occasions because you did not harvest enough food } \\
\text { or did not have money to buy food? }\end{array}$ & 35.5 & 25.6 & 30.5 \\
\hline 6. & $\begin{array}{l}\text { Have there been occasions when your household relied on } \\
\text { only a few kinds of low-cost food to feed children } \\
\text { because you were running out of food or did not have } \\
\text { enough money to buy food? }\end{array}$ & 57.4 & 84.0 & 70.9 \\
\hline 7. & $\begin{array}{l}\text { Did you (or family members living in this household) } \\
\text { ever cut the size of your meals or skip meals for at least } \\
\text { once every month between the planting and harvest } \\
\text { periods because there wasn't enough money for food? }\end{array}$ & 41.0 & 64.4 & 52.9 \\
\hline 8. & $\begin{array}{l}\text { Have all children living in this household not had enough } \\
\text { to eat because you did not have enough food or money to } \\
\text { buy food? }\end{array}$ & 30.3 & 44.8 & 37.7 \\
\hline 9. & $\begin{array}{l}\text { Have you (head of the family) not had enough money to buy } \\
\text { different types of food for your children to diversify } \\
\text { their meals? }\end{array}$ & 40.8 & 68.1 & 54.7 \\
\hline 10. & $\begin{array}{l}\text { Have any of the family members living in this household } \\
\text { ever eaten less than they felt you should } \\
\text { because there wasn't enough food? }\end{array}$ & 31.1 & 55.0 & 43.2 \\
\hline 11. & $\begin{array}{l}\text { Did you or other adults in your household ever not eat for } \\
\text { a whole day because there wasn't enough food or money to } \\
\text { buy food? }\end{array}$ & 6.9 & 12.8 & 9.8 \\
\hline 12. & $\begin{array}{l}\text { Have any of the children in this household lost weight } \\
\text { because you didn't have enough food or money } \\
\text { to buy food? }\end{array}$ & 31.1 & 35.4 & 33.2 \\
\hline
\end{tabular}

Note: Participants answered either yes or no to each of the questions. 